\title{
Infant feeding practices in Xinjiang Uygur Autonomous Region, People's Republic of China
}

\author{
Fenglian $\mathrm{Xu}^{1}{ }^{2}$, Colin Binns ${ }^{2, *}$, Jing $\mathrm{Wu}^{3}, \mathrm{Re} \mathrm{Yihan}^{4}, \mathrm{Yun} \mathrm{Zhao}^{2}$ and Andy Lee ${ }^{2}$ \\ ${ }^{1}$ Medical College of Shihezi University, Xinjiang 832002, People's Republic of China: ${ }^{2}$ School of Public Health, \\ Curtin University of Technology, GPO Box U1987, Perth, Western Australia 6845, Australia: ${ }^{3}$ Shihezi People's \\ Hospital, Xinjiang 832000, People's Republic of China: ${ }^{4}$ Urumqi Maternal and Child Health Care Institute, Xinjiang \\ 830000, People's Republic of China
}

Submitted 14 February 2005: Accepted 17 May 2006

\begin{abstract}
Aims: To document infant feeding methods in the first six months of life in Xinjiang Uygur Autonomous Region, People's Republic of China, 2003-2004. Some problems with breast-feeding in the area are explained.

Methods: A longitudinal study of infant feeding practices was undertaken. A total of 1219 mothers who delivered babies during 2003 and 2004 were interviewed in five hospitals or institutes, and after discharge were contacted in person or by telephone at approximately monthly intervals to obtain details of infant feeding practices. Multivariate logistic regression analysis was used to explore factors associated with breast-feeding initiation.

Results: 'Any breast-feeding' rates at discharge and at $0.5,1.5,2.5,3.5,4.5$ and 6 months were 92.2, 91.3, 89.9, 88.8, 87.7, 86.0 and 73.0\%, respectively. 'Exclusive breast-feeding' rates at discharge and at $0.5,1.5,2.5,3.5,4.5$ and 6 months were 66.2 , $47.6,30.1,25.8,22.1,13.0$ and $6.2 \%$, respectively. The main problem of breast-feeding in Xinjiang was the early introduction of formula or water. The average duration of 'exclusive breast-feeding' was 1.8 months (95\% confidence interval (CI) 1.7-2.0), of 'full breast-feeding' 2.8 months (95\% CI 2.7-2.9) and of 'any breast-feeding' 5.3 months (95\% CI 5.2-5.4).

Conclusions: Infant feeding methods in Xinjiang were documented in this study and the main problems with infant feeding in Xinjiang are discussed. Further studies are needed to identify factors associated with 'exclusive breast-feeding' and duration.
\end{abstract}

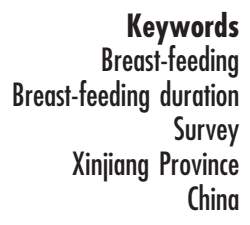

Breast-feeding is recognised as the most appropriate method for feeding infants and is closely related to health during infancy and to chronic disease prevention in adulthood $^{1,2}$. 'Exclusive breast-feeding' for the first six months of life and continued breast-feeding up to 2 years of age or beyond are recommended by the World Health Organization (WHO) and other authorities ${ }^{3}$.

There have been considerable changes in breastfeeding practices in China over the past 40 years. 'Ever breast-fed' rates in both urban and rural areas were over $80 \%$ in the 1950 s and 1960 s. But the rates started to decline considerably during the 1970s, especially in larger cities when the use of breast-milk substitutes became widespread. The 'ever breast-fed' rate in urban areas of China was $42.7 \%$ in 1975 and fell further to $33.6 \%$ in $1985^{4-6}$. A survey from a rural area near Shanghai showed that the breast-feeding rate was $80 \%$ in the early 1980 s and fell to $44 \%$ in the early $1990 s^{7}$. Thus the trends towards declining breast-feeding in urban and rural areas were similar; however, the rates in cities were lower.

To address the decline in breast-feeding, in the 1990s the Children's Development Plan of the Chinese government set a target to achieve a national 'exclusive breast-feeding' rate at 4 months of $80 \%$ by $2000^{8}$. As a result of the many efforts introduced to promote breast-feeding, including the baby-friendly hospital initiative, women and child health protection legislation, social support programmes and breast-feeding education programmes ${ }^{9}$, the breast-feeding rate in China started to increase in the $1990 \mathrm{~s}^{10}$. A survey undertaken in the Beijing Women's Hospital in 1990 showed that breast-feeding rates at 6 weeks were $79.2 \%$ in the rooming-in group and $39.8 \%$ in the control group ${ }^{11}$. In 2002, a cross-sectional study undertaken in Beijing and four provinces (Shandong, Hubei, Zhejiang, Guangdong) showed that the 'ever breast-fed' rate was $90.1 \%$ and the 'full breast-feeding' rates at 4 and 6 months were $45.3 \%$ and $21.6 \%$, respectively. The survey also documented that average duration of breast-feeding was $8.73 \pm 4.21$ months

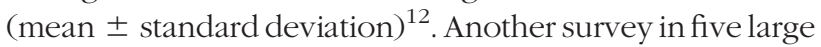
cities (Guangzhou, Shanghai, Congqing, Xian and Changchun) in 2002 showed that the average breast-feeding duration was 8 months and the 'any breast-feeding' rates at 0, 4, 6, 12 and 24 months were 94.6, 61.0, 50.1, 5.3 and 0.4\%, respectively ${ }^{13}$. From the report of the Third National Health 
Service Investigation in 2005, the breast-feeding initiation rates in urban and rural areas were 94.1 and 98.5\%, respectively. The average breast-feeding duration in urban and rural areas was 5 and 6 months, respectively ${ }^{14}$. The duration of breast-feeding in this survey was shorter than in the previous two, but the reason for this was not explained.

These studies show that breast-feeding rates in China fell during the 1970s, to reach the lowest point in the 1980s and began to rise in the 1990s. The rates in urban areas were generally lower than in rural areas. However China is a huge country, geographically as well as in population size and ethnic diversity, and breast-feeding rates in different parts of China can vary considerably ${ }^{15,16}$.

The Xinjiang Uygur Autonomous Region (Xinjiang AR) is located in north-western China. Situated in the hinterland of the Eurasian continent, Xinjiang borders eight countries: Russia, Kazakhstan, Kyrgyzstan, Tajikistan, Pakistan, Mongolia, India and Afghanistan. By the end of 2004, the population of Xinjiang had reached 19.6 million. The region contains more than 13 ethnic groups, the Uygur accounting for $45.73 \%$, the Han for $39.75 \%$ and the Kazakh for $7.04 \%$. The birth rate was 16 per thousand and death rate 5.1 per thousand.

A cross-sectional study undertaken in Shihezi, Xinjiang, in 1994-1996 showed that the breast-feeding rate was 34\% at 4 months $^{17}$, well below Chinese and international targets. This had significant implications for the health of the children of the region. A more detailed study of breastfeeding was needed to provide the data necessary to implement a comprehensive health promotion programme. The aim of the present longitudinal study was to identify the prevalence of breast-feeding up until 6 months of age.

\section{Methodology}

A longitudinal cohort study of infant feeding practices was undertaken in Xinjiang AR, People's Republic of China. In this region, all babies are usually delivered in hospitals. Mothers who delivered babies during 2003 and 2004 were contacted while in hospital and were invited to participate in the study. After discharge, mothers were contacted in person or by telephone at approximately monthly intervals (at $0.5,1.5,2.5,3.5,4.5$ and 6 months) using a structured questionnaire to obtain details of infant feeding practices.

A total of 1256 mothers were randomly recruited from five hospitals or institutes. In Shihezi People's Hospital, mothers were recruited every second day due to staffing constraints. In the other hospitals (Shihezi Maternal and Child Health Care Institute and Urumqi Maternal and Child Health Care Institute in urban areas; Chabuchaer Maternal and Child Health Care Institute and Yumin County Hospital in rural areas) all mothers were contacted. Almost all mothers who were contacted (1219 or 97\%) agreed to participate. Urumqi is the capital city of Xinjiang where the Uygur ethnic group is in the majority, while Shihezi is a predominantly Han ethnic area. Chabuchaer and Yumin counties have a larger concentration of Kazakh people and other minorities.

The majority of participants, including the minority groups, could read and speak Chinese (Mandarin). The questionnaire was originally prepared in Mandarin, and was also translated into the Uygur language, which can also be understood by Kazakh mothers. For those who could not read Chinese, trained nurses who were fluent in the ethnic languages were available to help them complete the questionnaires. For all minority mothers, follow-up calls and visits were made in their own ethnic language by nurses from their own ethnic group.

The questionnaire was based on those developed by Scott, Binns and Duong that have been used extensively in breast-feeding cohort studies in Australia, Vietnam and Kenya $^{18-23}$. The questionnaires were designed to identify the feeding method and to collect information on factors associated with breast-feeding. After translation the questionnaires were tested in focus groups to ensure cultural appropriateness.

The project was approved by Xinjiang local research authorities (Shihezi University, Urumqi Science Research Committee) and the Human Research Ethics Committee of Curtin University, Australia. Mothers who agreed to participate in the study signed the consent page at the front of the questionnaire and were informed of their rights to withdraw from the follow-up process at any time without prejudice. All of the personal data collected were kept confidential.

All data analyses were carried out using the Statistical Package for the Social Sciences, release 12.0 (SPSS Inc.). Descriptive statistics and cross-tabulations were generated for demographic factors, life tables were used for breastfeeding rates and the Kaplan-Meier model was used to calculated mean duration of 'exclusive breast-feeding', 'full breast-feeding' and breast-feeding.

The definitions of breast-feeding used in this paper are as follows ${ }^{24-26}$.

- Any breast-feeding: The infant receives breast milk (direct from the breast or expressed) with or without other drink, formula or other infant food.

- Exclusive breast-feeding: Breast-feeding while giving no other food or liquid, not even water, with the exception of drops or syrups consisting of vitamins, mineral supplements or medicine.

- Almost exclusive breast-feeding: The infant may receive small amounts of culturally valued supplements - water, water-based drinks, fruit juice and ritualistic fluids.

- Full breast-feeding: Includes 'exclusive breast-feeding' and 'almost exclusive breast-feeding'.

\section{Results}

The details of the sample and the prevalence of the major demographic variables are shown in Table 1. The sample 
Table 1 Demographic factors and breast-feeding percentage before discharge in Xinjiang, People's Republic of China, 2003$2004(n=1219)$

\begin{tabular}{|c|c|c|c|c|}
\hline Factor & $n$ & $\%$ & $\begin{array}{c}\text { Any } \\
\text { breast-feeding }\end{array}$ & $\begin{array}{c}\text { No } \\
\text { breast-feeding }\end{array}$ \\
\hline \multicolumn{5}{|l|}{ Ethnicity } \\
\hline Han & 578 & 47.4 & 89.3 & 10.7 \\
\hline Uygur & 360 & 29.5 & 94.7 & 5.3 \\
\hline Kazakh & 199 & 16.3 & 97.5 & 2.5 \\
\hline Other minorities & 82 & 6.7 & 97.6 & 2.4 \\
\hline \multicolumn{5}{|l|}{ Residence } \\
\hline Urban area & 909 & 74.6 & 91.7 & 8.3 \\
\hline Rural area & 310 & 25.4 & 95.8 & 4.2 \\
\hline \multicolumn{5}{|c|}{ Gestational age (weeks) } \\
\hline$<37$ & 39 & 4.1 & 92.3 & 7.7 \\
\hline$\geq 37$ & 917 & 95.9 & 96.6 & 3.4 \\
\hline \multicolumn{5}{|l|}{ Birth weight (g) } \\
\hline$<2500$ & 37 & 3.2 & 86.5 & 13.5 \\
\hline 2500-3999 & 1019 & 87.2 & 94.6 & 5.4 \\
\hline$\geq 4000$ & 112 & 9.6 & 94.6 & 5.4 \\
\hline \multicolumn{5}{|l|}{ Delivery method } \\
\hline Vaginal & 602 & 52.9 & 94.7 & 5.3 \\
\hline Caesarean & 537 & 47.1 & 93.9 & 6.1 \\
\hline \multicolumn{5}{|l|}{ Birth order } \\
\hline 1 & 924 & 82.3 & 96.3 & 3.7 \\
\hline$\geq 2$ & 199 & 17.7 & 98.5 & 1.5 \\
\hline \multicolumn{5}{|l|}{ Baby's gender } \\
\hline Male & 616 & 52.3 & 92.2 & 7.8 \\
\hline Female & 561 & 47.7 & 93.6 & 6.4 \\
\hline \multicolumn{5}{|c|}{ Maternal age (years) } \\
\hline$<25$ & 184 & 16.7 & 98.9 & 1.1 \\
\hline $25-29$ & 544 & 49.4 & 96.7 & 3.3 \\
\hline $30-34$ & 307 & 27.9 & 96.7 & 3.3 \\
\hline$\geq 35$ & 66 & 6.0 & 93.9 & 6.1 \\
\hline \multicolumn{5}{|c|}{ Maternal education (years) } \\
\hline$<9$ & 476 & 41.9 & 98.3 & 1.7 \\
\hline $10-12$ & 305 & 26.8 & 94.8 & 5.2 \\
\hline$\geq 13$ & 355 & 31.3 & 96.6 & 3.4 \\
\hline \multicolumn{5}{|l|}{ Maternal job } \\
\hline Housewife & 500 & 43.7 & 95.4 & 4.6 \\
\hline Sales & 155 & 13.5 & 89.0 & 11.0 \\
\hline Worker & 119 & 10.4 & 95.0 & 5.0 \\
\hline Farmer & 95 & 8.3 & 94.7 & 5.3 \\
\hline Office worker & 249 & 21.8 & 96.8 & 3.2 \\
\hline Other & 26 & 2.3 & 96.2 & 3.8 \\
\hline \multicolumn{5}{|c|}{ Annual family income (RMB) } \\
\hline$<10000$ & 309 & 33.5 & 98.4 & 1.6 \\
\hline $10000-19999$ & 356 & 38.6 & 97.5 & 2.5 \\
\hline$\geq 20000$ & 258 & 28.0 & 95.3 & 4.7 \\
\hline
\end{tabular}

as recruited included 47\% Han, 30\% Uygur, 16\% Kazakh and a small number of other minorities. Almost all of the mothers (1118) in the study were married, eight were separated and one was widowed.

The breast-feeding rates were calculated by life table analysis and are detailed in Table 2. The breast-feeding initiation rate was $92 \%$ and by 6 months this had declined to $73 \%$. The median duration of 'exclusive breast-feeding' was less than 1 month, of 'full breast-feeding' was 2.8 months, and of 'any breast-feeding' was greater than 6 months. As follow-up in this study was terminated at 6 months, the maximum duration of breast-feeding could not be determined. The average duration of 'exclusive breast-feeding' was 1.8 months ( $95 \%$ confidence interval (CI) 1.7-2.0) and of 'full breast-feeding' was 2.8 months
(95\% CI 2.7-2.9). At 6 months of age, 73\% (CI 70.1-75.8) of infants were still receiving some breast milk.

Inevitably in a cohort study, some mothers were lost to follow-up. The percentage of mothers lost to follow-up at $0.5,1.5,2.5,3.5,4.5$ and 6 months was $6,7,9,12,13$ and $21 \%$, respectively.

Mother's perceptions about breast-feeding duration and formula are shown in Table 3. The majority of mothers thought that breast milk was not enough for their baby's nutritional requirements by 6 months of age. Only 33\% of mothers thought that breast milk could satisfy a baby's nutritional requirements at 6 months and 31\% mothers planned to give their baby supplemental food before 4 months.

The perceptions of the different ethnic groups were compared using binary logistic and multinomial logistic regression analysis, and more minority mothers were found to have incorrect perceptions about 'exclusive breastfeeding' duration and formula. For example, compared with Han mothers, minority mothers were less likely to consider that breast milk could satisfy a baby's nutritional requirements for more than 4 months (odds ratio $(O R)=0.4$, 95\% CI 0.2-0.5) and were more likely to plan giving their babies supplemental food before 4 months (OR $=14.6,95 \%$ CI 10.2-21.1). Kazakh mothers more likely thought formula was a healthy food (OR $=3.1,95 \%$ CI 1.3-8.1).

A comparison was made of the understanding of infant feeding of mothers from urban and rural areas. More mothers in rural areas (92.7\%) thought that breast-feeding could satisfy the baby's requirements for more than 4 months compared with mothers in urban areas (80.4\%) $\left(\chi^{2}=22.7, P<0.01\right)$. Fewer mothers in rural areas $(6.8 \%)$ planned to start giving supplemental food to their babies before 4 months than mothers in urban areas (41.3\%) $\left(\chi^{2}=90.0, P<0.01\right)$. Overall, $8.5 \%$ of mothers who were breast-feeding their babies were recommended to begin using additional infant food by medical staff and a similar percentage by other people, i.e. $17 \%$ in total.

\section{Discussion}

In Xinjiang AR, 92\% of mothers were breast-feeding on discharge from hospital and $73 \%$ were still breast-feeding at 6 months. This is a considerable increase in the breastfeeding rate compared with the previous study in Shihezi in 1996, when the rate at 4 months was only $34 \%{ }^{17}$. The breast-feeding rate in Xinjiang at discharge was similar to that currently reported from Beijing and some inland provinces, and for breast-feeding at 6 months was higher than in those regions ${ }^{12}$. The only Chinese province with a higher reported breast-feeding rate over the first six months was Tibet, but the 'exclusive breast-feeding' rate in Xinjiang was a little higher than that in Tibet $^{27}$. The breastfeeding initiation rate was a similar to that in Australia ${ }^{18,28}$, which is higher than in Canada and the USA ${ }^{29,30}$.

However, the 'exclusive breast-feeding' rate in Xinjiang was considerably lower than the target of $80 \%$ at 4 months 
Table 2 Breast-feeding rates (\%) in Xinjiang, People's Republic of China, 2003-2004 $(n=1219)$

\begin{tabular}{|c|c|c|c|c|}
\hline Baby's month & $n$ & Exclusive breast-feeding & Full breast-feeding & Any Breast-feeding \\
\hline $0^{*}$ & 1219 & 66.2 & 88.3 & 92.2 \\
\hline 0.5 & 1147 & 47.6 & 66.3 & 91.3 \\
\hline 1.5 & 1136 & 30.1 & 55.6 & 89.9 \\
\hline 2.5 & 1105 & 25.8 & 46.9 & 88.8 \\
\hline 3.5 & 1075 & 22.1 & 36.1 & 87.7 \\
\hline 4.5 & 1055 & 13.0 & 16.8 & 86.0 \\
\hline 6 & 964 & 6.2 & 7.9 & 73.0 \\
\hline
\end{tabular}

* 0 month refers to the time of discharge from hospital, which was generally one week postpartum.

set by the Chinese government. Many babies were given water, formula or cow's milk too early in their life. The early introduction of complementary foods may shorten breast-feeding duration ${ }^{31}$.

The main reason for the early introduction of water may be an inappropriate understanding of infant feeding by both medical staff and mothers. Feeding water was common in hospitals because many doctors thought that infant jaundice was associated with dehydration. Also, Xinjiang is a province where people live on the edge of desert and traditionally mothers feed baby water to their infants early in life. The early introduction of water is also common in Tibet ${ }^{27}$. Because the majority of babies there were fed water, the 'exclusive breast-feeding' rate was very small and hence in that study more emphasis was placed on the 'full breast-feeding' rate in the analysis. The 'full breastfeeding' rate at 4-6 months was only 3.0\% in urban areas and $12.8 \%$ in rural areas in Tibet ${ }^{27}$. The 'full breast-feeding' rate in Shihezi was slightly higher than this at $7.9 \%$.

The advertising and ready availability of infant formula could be factors in its early introduction to some infants. In this study, most mothers knew about formula and about one mother in 10 was recommended to use infant foods by the medical staff while she was still in hospital. Only onethird of mothers thought that breast-feeding could satisfy a baby's nutritional requirements until 6 months of age and there would be no need for other supplemental foods. Some Uygur mothers said: 'Breast milk is not thick enough for baby's growth'. The majority of babies (65.1\%) were fed formula as a complement to breast-feeding at 6 months of age. The average time for the introduction of solid foods in the Han and minority groups were 4.7 and 5.7 months, respectively ${ }^{32}$.

The main problem of breast-feeding in Xinjiang was the early introduction of formula or water. The WHO recommends that infants should be fed exclusively on breast milk from birth to 6 months of age, with no water or other liquids or food during this period ${ }^{33}$. Education should highlight 'exclusive breast-feeding' and correct some old misconceptions.

There are several limitations that need to be considered when interpreting the results of this study. While the sample included urban and rural areas, logistically it was not possible to include subjects from the very remote or

Table 3 Mother's perceptions about breast-feeding and formula in Xinjiang, People's Republic of China, 2003-2004 ( $n=1219)$

\begin{tabular}{|c|c|c|c|c|c|c|c|c|c|c|}
\hline \multirow[b]{2}{*}{ Question } & \multicolumn{2}{|c|}{ Han } & \multicolumn{2}{|c|}{ Uygar } & \multicolumn{2}{|c|}{ Kazakh } & \multicolumn{2}{|c|}{ Others } & \multicolumn{2}{|c|}{ Total } \\
\hline & $n$ & $\%$ & $n$ & $\%$ & $n$ & $\%$ & $n$ & $\%$ & $n$ & $\%$ \\
\hline \multicolumn{11}{|c|}{ How long can breast-feeding satisfy all of a baby's nutritional requirements? } \\
\hline$<4$ months & 47 & 9.4 & 101 & 29.5 & 24 & 13.3 & 9 & 12.3 & 181 & 16.5 \\
\hline 4 months & 242 & 48.2 & 201 & 58.8 & 60 & 33.3 & 24 & 32.9 & 527 & 48.0 \\
\hline 6 months & 201 & 40.0 & 40 & 11.7 & 87 & 48.3 & 33 & 45.2 & 361 & 32.9 \\
\hline$>6$ months & 12 & 2.4 & 0 & 0.0 & 9 & 5.0 & 7 & 9.6 & 28 & 2.6 \\
\hline Total & 502 & 100.0 & 342 & 100.0 & 180 & 100.0 & 73 & 100.0 & 1097 & 100.0 \\
\hline \multicolumn{11}{|c|}{ At what age do you plan to start giving your baby supplemental food? } \\
\hline$<4$ months & 41 & 8.0 & 255 & 80.4 & 41 & 24.0 & 2 & 2.7 & 339 & 31.4 \\
\hline $4-5$ months & 233 & 45.2 & 23 & 7.3 & 28 & 16.4 & 34 & 45.3 & 318 & 29.5 \\
\hline 6 months & 171 & 33.2 & 27 & 8.5 & 57 & 33.3 & 15 & 20.0 & 270 & 25.0 \\
\hline$>6$ months & 41 & 8.0 & 4 & 1.3 & 23 & 13.5 & 10 & 13.3 & 78 & 7.2 \\
\hline Don't know & 29 & 5.6 & 8 & 2.5 & 22 & 12.9 & 14 & 18.7 & 73 & 6.8 \\
\hline Total & 515 & 100.0 & 317 & 100.0 & 171 & 100.0 & 75 & 100.0 & 1078 & 100.0 \\
\hline \multicolumn{11}{|l|}{ What is infant formula? } \\
\hline Breast-milk substitute & 373 & 72.9 & 273 & 80.1 & 74 & 41.6 & 53 & 68.8 & 773 & 69.8 \\
\hline Healthy food & 25 & 4.9 & 42 & 12.3 & 26 & 14.6 & 6 & 7.8 & 99 & 8.9 \\
\hline Don't know & 114 & 22.3 & 26 & 7.6 & 78 & 43.8 & 18 & 23.4 & 236 & 21.3 \\
\hline Total & 512 & 100.0 & 341 & 100.0 & 178 & 100.0 & 77 & 100.0 & 1108 & 100.0 \\
\hline \multicolumn{11}{|c|}{ Compared with breast milk, formula is: } \\
\hline Not so good & 429 & 84.8 & 296 & 87.3 & 136 & 80.5 & 67 & 87.0 & 928 & 85.1 \\
\hline The same & 77 & 15.3 & 43 & 12.7 & 33 & 19.6 & 10 & 13 & 163 & 14.9 \\
\hline Total & 506 & 100.0 & 339 & 100.0 & 169 & 100.0 & 77 & 100.0 & 1091 & 100.0 \\
\hline
\end{tabular}


nomadic areas of the province. However, only a small proportion of the population lives in these areas.

\section{Conclusion}

The present study documents infant feeding patterns in Xinjiang and highlights the main ways in which they differ from national and international best practices. 'Any breastfeeding' rates at discharge and at 6 months were 92.2 and $73.0 \%$, respectively. 'Exclusive breast-feeding' rates at discharge and 6 months were 66.2 and $6.2 \%$, respectively. The main problem of breast-feeding in Xinjiang was the early introduction of formula or water. Further studies are needed to identify factors associated with 'exclusive breast-feeding' and duration.

\section{Acknowledgements}

We gratefully acknowledge the willing assistance given by the mothers in our study, the hospital staff and nursing students. Without this assistance the study would not have been possible.

\section{References}

1 World Health Organization. Effect of breastfeeding on infant and child mortality due to infectious diseases in less developed countries: a pooled analysis. Lancet 2000; 355: 451-5.

2 Binns CW, Lee M, Scott JA. The fetal origins of disease hypothesis: public health implications for the Asia-Pacific region. Asia Pacific Journal of Public Health 2001; 13: 68-73.

3 World Health Organization (WHO). Report of the Expert Consultation on the Optimal Duration of Exclusive Breastfeeding. Geneva: WHO, 2001; 28-30.

4 Wang F, Zhu Z, Tong F. Discussion and suggestion about promoting national breastfeeding. Maternal and Child Health Care of China 1991; 6: 6-8.

5 Chen J, Ji P. Process to promote breastfeeding in Beijing. Maternal and Child Health Care of China 1993; 8: 27 .

6 Buxton KE, Gielen AC, Faden RR, Brown CH, Paige DM, Chwalow AJ. Women intending to breastfeed: predictors of early infant feeding experiences. American Journal of Preventive Medicine 1991; 7: 101-6.

7 Pang R. Baby friendly hospital improve breastfeeding. Maternal and Child Health Care of China 1993; 8: 2-3.

8 Niu X, Zhao Y, Liu Q. Education Outline of Chinese Children's Development Plan in 1990s. Beijing: Central Broadcasting and Television University Publication, 1993.

9 Song L. International breastfeeding week. Maternal and Child Health Care of China 1999; 14: 562.

10 Zheng S. Initiate baby friendly hospital, promote breastfeeding. Maternal and Child Health Care of China 1993; 8: $18-9$.

11 Huang X, Cong K, Zhang Z. Reform obstetric rule, promote breastfeeding. Maternal and Child Health Care of China 1993; 8: $21-4$

12 Zhang W, Hao B, Wang L. Breastfeeding in Beijing and four provinces in China. Chinese Journal of Health Education 2004; 20: 14-6.
13 Hu B, Zhang C, Li Y, Zhang Y, Feng Z. Breastfeeding and associated factors in 5 cities, China. Maternal and Child Health Care of China 2004; 19: 18-20.

14 Bureau $\mathrm{H}$. Abstract of the report on the 3rd national health service investigation and analysis. Chinese Hospitals 2005; 9: $6-7$.

15 Wang $\mathrm{F}$, $\mathrm{Xu} \mathrm{H}$, Meng $\mathrm{P}$. Breastfeeding condition and influence factors in 4 to 6 month babies in Hubei province. Maternal and Child Health Care of China 2000; 15: 624-6.

16 Yun YP, Kang ZS, Ling LJ, Xin QC. Breast feeding of infants between $0-6$ months old in 20 provinces, municipalities and autonomous regions in the People's Republic of China. Journal of Tropical Pediatrics 1989; 35: 277-80.

17 Xiao C. Breastfeeding in Shinezi. China Primary Health Care 1998; 13: 151-2.

18 Scott JA, Landers MC, Hughes RM, Binns CW. Factors associated with breastfeeding at discharge and duration of breastfeeding. Journal of Paediatrics and Child Health 2001; 37: 254-61.

19 Scott JA, Aitkin I, Binns CW, Aroni RA. Factors associated with the duration of breastfeeding amongst women in Perth, Australia. Acta Paediatrica 1999; 88: 416-21.

20 Duong DV, Binns CW, Lee AH. Breast-feeding initiation and exclusive breast-feeding in rural Vietnam. Public Health Nutrition 2004; 7: 795-9.

21 Li L, Zhang M, Scott JA, Binns CW. Factors associated with the initiation and duration of breastfeeding by Chinese mothers in Perth, Western Australia. Journal of Human Lactation 2004; 20: 188-95.

22 Lakati A, Binns C, Stevenson M. The effect of work status on exclusive breastfeeding in Nairobi. Asia Pacific Journal of Public Health 2002; 14: 85-90.

23 Lakati A, Binns C, Stevenson M. Breast-feeding and the working mother in Nairobi. Public Health Nutrition 2002; 5: $715-8$.

24 Binns CW. Encourage and support breastfeeding. Journal of the Home Economics Institute of Australia 2004; 11: 28-38.

25 Labbok M, Krasovec K. Toward consistency in breastfeeding definitions. Studies in Family Planning 1990; 21: 226-30.

26 Binns CW, Scott J. Breastfeeding: reasons for starting, reasons for stopping and problems along the way. Breastfeed Review 2002; 10: 13-9.

27 Dang S, Yan H, Wang X, Zheng L, Xie H. Breastfeeding survey in Tibet. Maternal and Child Health Care of China 2001; 16: 744-7.

28 Scott J, Landers M, Hughes R, Binns CW. Psychosocial factors associated with the abandonment of breastfeeding prior to hospital discharge. Journal of Human Lactation 2001; 17: $24-30$.

29 Dubois L, Girard M. Social determinants of initiation, duration and exclusivity of breastfeeding at the population level: the results of the Longitudinal Study of Child Development in Quebec (ELDEQ 1998-2002). Canadian Journal of Public Health 2003; 94: 300-5.

30 Philipp BL, Merewood A, Miller LW, Chawla N, MurphySmith MM, Gomes JS, et al. Baby-friendly hospital initiative improves breastfeeding initiation rates in a US hospital setting. Pediatrics 2001; 108: 677-81.

31 Riva E, Banderali G, Agostoni C, Silano M, Radaelli G, Giovannini M. Factors associated with initiation and duration of breastfeeding in Italy. Acta Paediatrica 1999; 88: 411-5.

32 Yu H, Song J. Breastfeeding among 368 infants in Karamay city, Xinjiang. Chinese Journal of Health Education 2000; 16: $581-3$.

33 World Health Organization (WHO). Global Strategy for Infant and Young Child Feeding [online]. Geneva: WHO, 2003; 14. Available at http://www.who.int/child-adoles cent-health/New_Publications/NUTRITION/gs_iycf.pdf. Accessed 18 October 2006. 